\title{
Medical Image of the Week: Migration of Fractured PICC Line
}

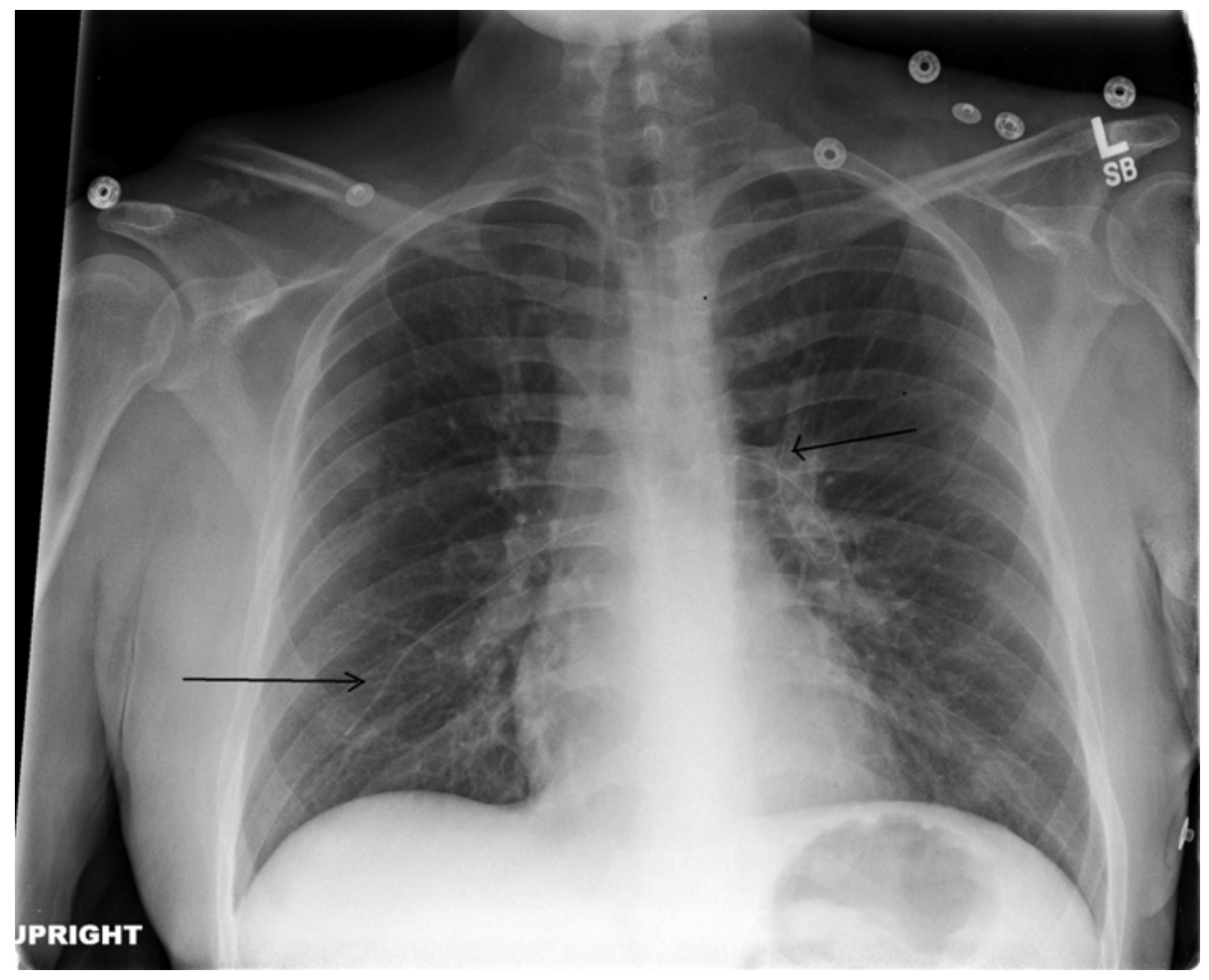

Figure 1. Chest radiograph showing catheter fragment coiled within the main pulmonary artery with the tips extending to the peripheral pulmonary vasculature (arrow).

A 29 year old man had a peripherally inserted central catheter (PICC, $60 \mathrm{~cm}, 4 \mathrm{Fr}$, single lumen Groshong), placed at a rural hospital via right brachial vein approach for long term antibiotic therapy for an infected diabetic foot. Two days later, nursing staff noticed difficulty in flushing the PICC line. A chest X-ray was obtained which showed fracture of a portion of the PICC line with migration to the pulmonary vasculature (Figure 1). The broken catheter was successfully removed in a two-step process using a $6 \times 10$ mm EN Snare ${ }^{\circledR}$ from the left pulmonary artery. The patient, however remained asymptomatic and without any arrhythmias on the telemonitor. Intravascular migration and subsequent malposition of PICC lines are usually due to their pinch off, small size, as well as changes in intrathoracic pressure and body position (1).

Santhosh G. John MD, Paola Devis MD

University of Arizona

Tucson, Arizona

\section{Reference}

1. Zhang $\mathrm{Y}$, Jiang $\mathrm{H}$, Wei $\mathrm{L}, \mathrm{Yu} \mathrm{H}$. Persistent hiccup Caused by peripherally inserted central catheter migration. J Anesth. 2011;25(4):625-6. [CrossRef] [PubMed] 